\title{
Tomographic image of low $P$ velocity anomalies above slab in northern Cascadia subduction zone
}

\author{
Dapeng Zhao ${ }^{1}$, Kelin Wang ${ }^{2}$, Garry C. Rogers ${ }^{2}$, and Simon M. Peacock ${ }^{3}$ \\ ${ }^{1}$ Department of Earth Sciences, Ehime University, Matsuyama 790-8577, Japan \\ ${ }^{2}$ Pacific Geoscience Centre, Geological Survey of Canada, 9860 W Saanich Rd, Sidney, B.C., Canada V8L $4 B 2$ \\ ${ }^{3}$ Department of Geology, Box 871404, Arizona State University, Tempe, AZ 85287-1404, U.S.A.
}

(Received June 29, 1999; Revised September 23, 2000; Accepted September 25, 2000)

\begin{abstract}
At the Cascadia margin the Juan de Fuca plate is subducting beneath the North America plate, causing active seismicity within both plates. Earthquakes occur down to a maximum depth of $80 \mathrm{~km}$ within the descending oceanic plate and to about $30 \mathrm{~km}$ in the overriding continental plate. We use a method of seismic tomography to invert 28,230 $P$ wave arrival times from 2666 local earthquakes that occurred in and around Vancouver Island from 1970 to 1990 . The tomography model uses about $30 \mathrm{~km}$ horizontal and $12-19 \mathrm{~km}$ vertical grid spacing and assumes that the seismic velocity perturbations vary continuously between grid points. Velocity structures can be obtained to a depth of $65 \mathrm{~km}$. The obtained tomographic image shows an extensive low velocity zone above the subducted slab at about $45 \mathrm{~km}$ depth and patches of low velocities at shallower depths just seaward of the volcanic front. The deeper extensive low velocity zone may indicate the presence of partially hydrated mantle, most likely serpentinite, as a result of slab dehydration associated with the transformation of metabasalt to eclogite. One of the shallow low velocity patches coincides with an abrupt increase in surface heat flow and may reflect the presence of partial melts or water in the crust.
\end{abstract}

\section{Introduction}

The Juan de Fuca plate is subducting beneath the North America plate at a rate of about $4.5 \mathrm{~cm} / \mathrm{yr}$ at the Cascadia continental margin (Fig. 1). The method of seismic tomography has been used to study the structure of the crust and upper mantle in this subduction zone. Using teleseismic $P$ wave arrivals, Bostock and VanDecar (1995), Michaelson and Weaver (1986), Rasmussen and Humphreys (1988), VanDecar (1991), Harris et al. (1991), and Benz et al. (1992) studied the upper mantle structure beneath various areas along the margin. They imaged the subducted segments of the Juan de Fuca plate system to depths of 300-500 km, and showed that at these depths, the slab dip ranged from $45^{\circ}$ $65^{\circ}$ in southern British Columbia and central Washington to $70^{\circ}$ just north of the Mendocino triple junction. Threedimensional (3-D) local-earthquake tomography has been applied to a few areas to study the shallow structure of the Cascadia region (Fig. 1). Lees and Crosson (1989, 1990), Verdonck and Zandt (1994), Moran et al. (1999), and Stanley et al. (1999) determined the 3-D crustal structure in the Mount St. Helens, Mount Rainier, and Puget Sound regions in Washington and the Mendocino triple junction area in northern California. These local-earthquake tomography results revealed significant lateral heterogeneities in the crust and upper mantle and their correlations with local geological features. In this paper, we report preliminary results of a 3-D local earthquake seismic tomography in the Vancouver Island area, southwestern British Columbia.

Copy right $(\mathrm{C}$ The Society of Geomagnetism and Earth, Planetary and Space Sciences (SGEPSS); The Seismological Society of Japan; The Volcanological Society of Japan; The Geodetic Society of Japan; The Japanese Society for Planetary Sciences.
Our area of study (Fig. 1), especially southern Vancouver Island where the Canadian Lithoprobe geoscience program laid its first transect, has been the focus of extensive geophysical research. The upper surface of the descending Juan de Fuca plate is well located by multichannel seismic reflection studies offshore and to a depth of approximately $30 \mathrm{~km}$ under western Vancouver Island (Davis and Hyndman, 1989; Hyndman et al., 1990; Spence et al., 1991). The slab geometry is constrained by Wadati-Benioff seismicity (Rogers, 1983; Taber and Smith, 1985; Crosson and Owens, 1987; Rogers et al., 1990) and receiver function analysis (Cassidy and Ellis, 1993) to about $80 \mathrm{~km}$ depth and by teleseismic tomography to greater depths (Bostock and VanDecar, 1995). Seismic surveys conducted on Vancouver Island and the adjacent mainland have identified a number of faults that divide this region into different terranes and significant variations in crustal velocity (Zelt et al., 1993, 1996; Hyndman, 1995; Clowes et al., 1996; Spence and McLean, 1999). Gravity modeling studies have provided constraints on density contrasts between different terranes (Riddihough, 1979; Clowes et al., 1997).

Magnetotelluric survey and modeling (Kurtz et al., 1986, 1990) revealed a landward dipping highly conductive zone in the $20-50 \mathrm{~km}$ depth range beneath southern Vancouver Island. The high conductivity zone was originally interpreted as the subducted oceanic crust but later recognized to be in the lower crust and mantle wedge above the slab. The high-conductivity zone appears to coincide with a band containing numerous seismic reflectors (the " $E$ layer"). Cassidy and Ellis $(1991,1993)$ showed that both the $E$ layer and the subducted oceanic crust were regions of low shear-wave ve- 


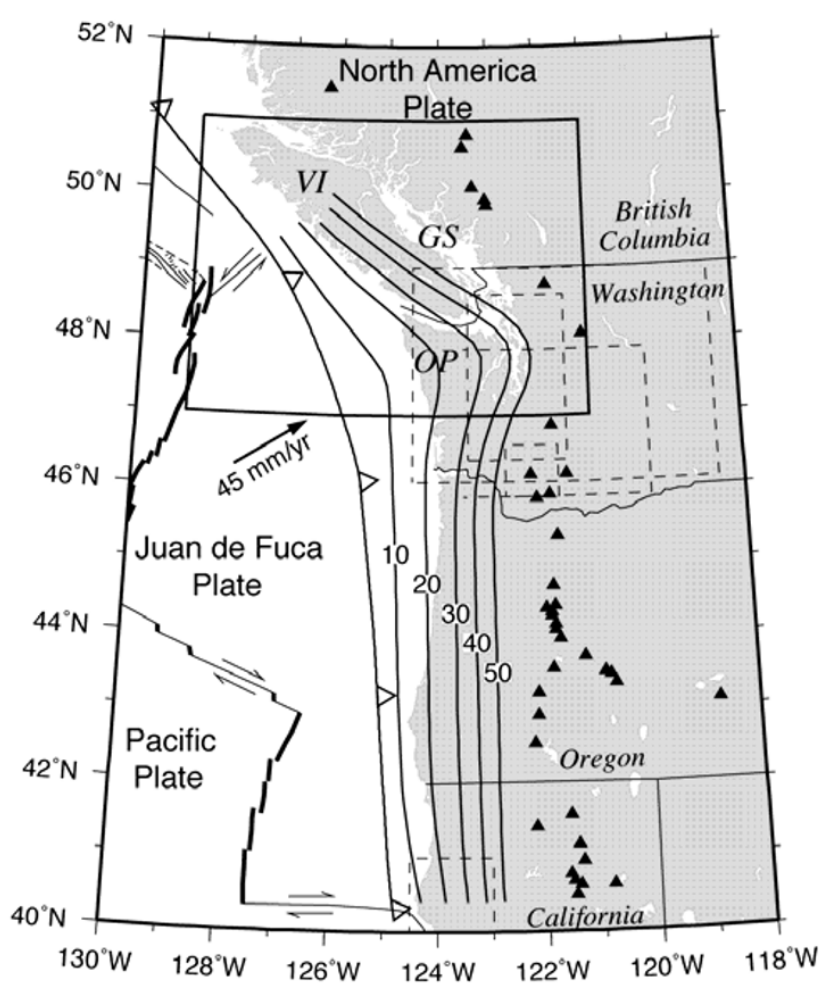

Fig. 1. The Cascadia subduction zone and areas of previous (dashed) and present (solid) local-earthquake tomography studies. Previous studies in Washington were done by, in ascending order of area sizes, Lees and Crosson (1989, 1990), Moran et al. (1999), and Stanley et al. (1999). The study in California was done by Verdonck and Zandt (1994). Holocene volcanoes are shown as solid triangles. Contours (in $\mathrm{km}$ ) of the position of the top of the subducted slab are from Flück et al. (1997). VI is Vancouver Island, GS is Georgia Strait, OP is Olympic Peninsula.

locities. The high electric conductivity and low velocity may indicate the presence of water (Hyndman, 1988) or hydrated materials in the mantle wedge. In the present study, we identify a number of low seismic velocity anomalies in the forearc and comment on their distribution. The resolution of seismic tomography does not yet permit detailed imaging of terrane structure and velocity boundaries, but the tomographic image provides a regional, 3-D view of the long-wavelength velocity structure that complements other detailed geophysical studies along individual corridors or around single sites.

\section{Data}

We have used $P$ wave arrival times picked from digital data recorded by the Western Canada Telemetered Seismic Network operated by the Geological Survey of Canada (GSC) and the University of British Columbia in the period from March 1970 to December 1990. The GSC routinely locates earthquakes in Canada and in the USA within 25 $\mathrm{km}$ of the Canada-USA border. We have also used arrival times for earthquakes in the GSC data set at stations in the Olympic Peninsula and Puget Sound operated by the University of Washington. Similarly we have used arrival times at Canadian stations from larger earthquakes in the USA for which solutions have been published by the University of Washington. A total of 77 stations were used in this study. Figure 2 shows the station distribution, together with the plan

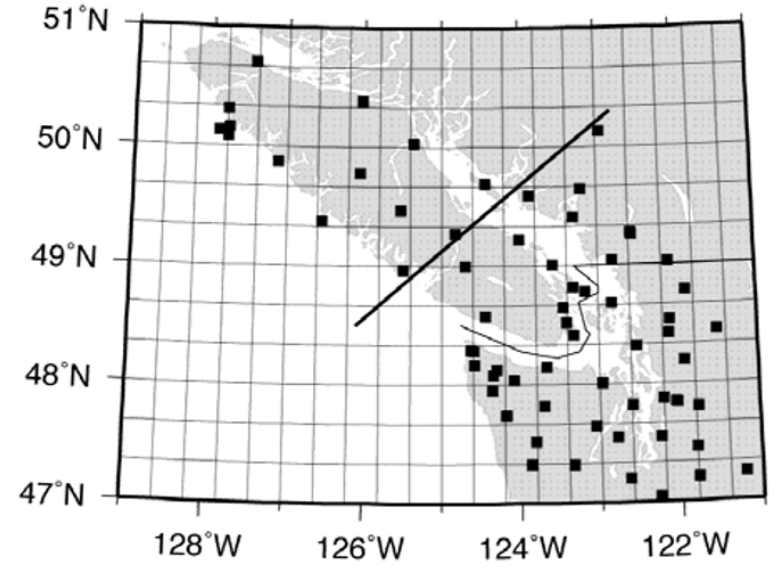

Fig. 2. Locations of the seismic stations used in the present study and the map view of the grid used for tomographic inversion. Nodal points, where velocity perturbations are determined by inversion, are at the intersection of grid lines. The same grid sheet is constructed at depths 3, 15, 29, 46, and $65 \mathrm{~km}$ to yield a 3-D grid of 1200 nodes. The straight thick line indicates the location cross section shown in Fig. 8.

view of the grid to be used for tomographic inversion in this work. Most of the stations are located in the southern part of the study area. A few stations fall out of the grid area and are not shown in Fig. 2.

More than 3100 earthquakes were recorded by the seismic network from 1970 to 1990 . We selected earthquakes for our tomographic inversion on the basis of the following three criteria. (1) $P$ arrivals were clearly recorded by at least 7 stations. (2) Standard errors for hypocentral locations were less than $4 \mathrm{~km}$. (3) The epicenters were within $40 \mathrm{~km}$ of land, in order to avoid possible systematic location errors in offshore earthquakes due to all the seismograph stations being located to one side (e.g., Wahlstrom and Rogers, 1992). However, the first two criteria were not strictly applied in regions of very low seismicity because we tried to keep the hypocenter distribution as uniform as possible. Some earthquakes were selected for this reason even though they had only 6 arrivals. Figure 3 shows the hypocentral distributions of the 2666 selected events. Continental crustal earthquakes occur to a depth of about $30 \mathrm{~km}$. Earthquakes in the subducted Juan de Fuca plate form a Wadati-Benioff zone to about 80 km depth (Fig. 3(b)). Shallow slab events are mainly along the Pacific coast and around southern Vancouver Island and the adjacent mainland. An artificial concentration of events near the surface is created by the velocity jump at a depth of $6 \mathrm{~km}$ in the one-dimensional (1-D) velocity model (Fig. 4) used by the GSC for routine hypocenter location in this area. Most of the deeper earthquakes occurred beneath Georgia Strait. The significant reduction in earthquake density south of about latitude $48^{\circ} \mathrm{N}$ is artificial since this is the southern boundary of the GSC data set. From south of this boundary, only earthquakes larger than about $\mathrm{M}=2.5$ that were recorded all across the GSC array have been included.

Figure 5(a) shows the number of earthquakes versus focal depth, and Fig. 5(b) shows the number of $P$ wave arrival times versus epicentral distance. Most arrival times have epicentral distances from 30 to $150 \mathrm{~km}$. Very few arrivals have epicentral distances larger than $360 \mathrm{~km}$. There are a 


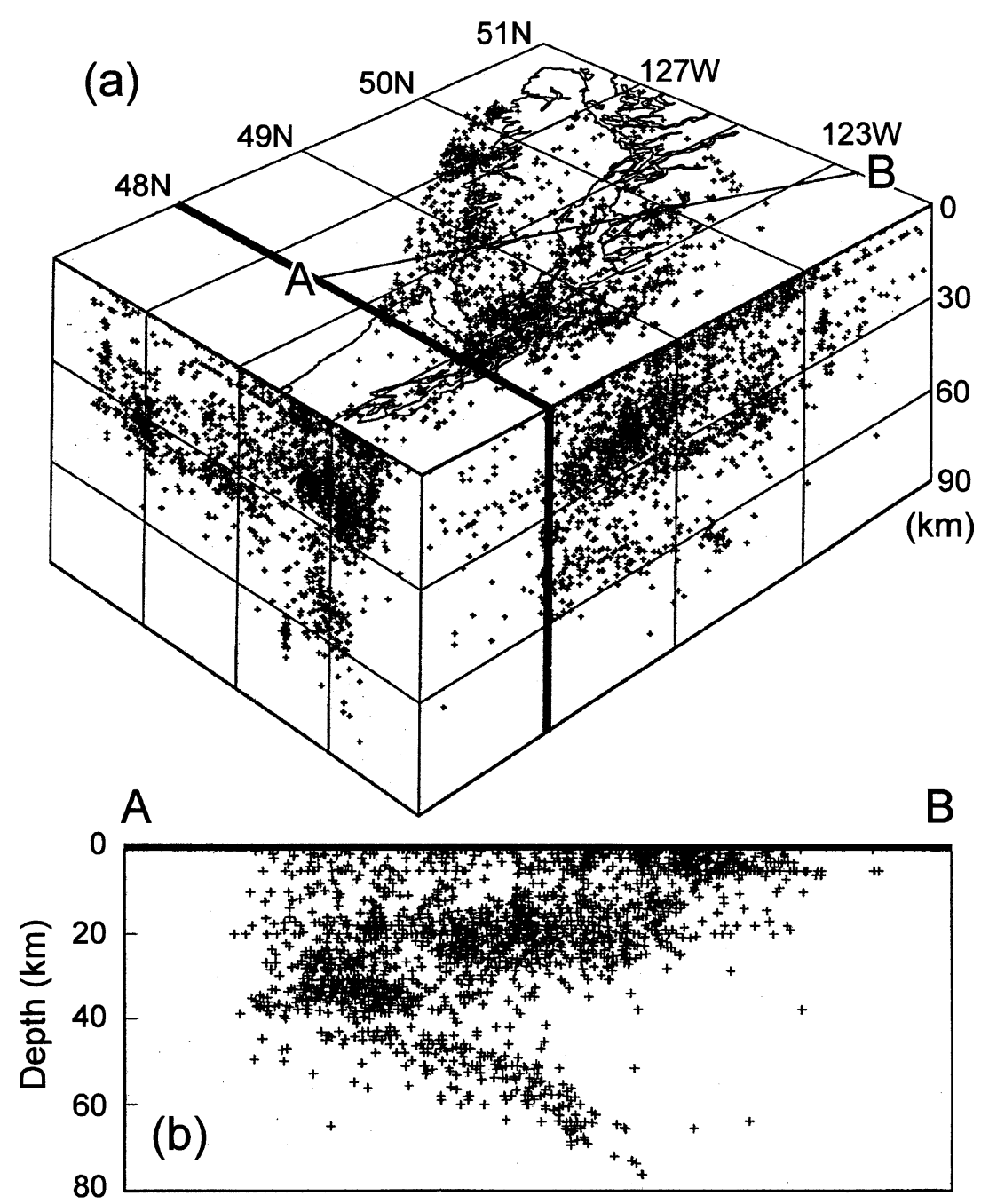

Fig. 3. (a) A 3-D view of the 2666 earthquakes used in this study. The data set is truncated off west coast of Vancouver Island, and only the largest events are used south of $48^{\circ}$ which is the limit of the GSC data set. The hypocenters have been projected onto the three shown surfaces of the box. (b) All hypocenters projected onto a cross section along the profile A-B shown in (a).

total of 28,230 $P$ wave arrivals. The accuracy of arrival time picks is estimated to be $0.1-0.2 \mathrm{~s}$ for most of the data and slightly lower $(0.2-0.3 \mathrm{~s})$ if the epicentral distance is greater that $200 \mathrm{~km}$.

\section{Tomographic Inversion}

We used the tomographic method of Zhao et al. (1992) to invert the arrival time data to determine the $P$-wave velocity $\left(V_{p}\right)$ structure. The inversion makes adjustments (perturbations) to a starting velocity model such that the difference between the predicted and observed arrival times is minimized in the least squares sense. The model space is discretized using a 3-D grid, and the velocity perturbations are parameterized using values at grid nodes. Between grid nodes, the velocity perturbation at any point is defined by interpolating the values at the eight grid nodes surrounding that point. A continuous velocity perturbation field is then completely represented by the set of nodal values. The parameters to be determined are the velocity perturbation $\left(\triangle V_{p}\right)$ from the starting model at each grid node and four hypocentral parameters for each earthquake (three coordinates and origin time). Our velocity parameterization is very different from the block approach used in other local-earthquake tomography studies along the Cascadia subduction zone (Fig. 1). In the block approach the earth is divided into many small blocks, each having a uniform seismic velocity value. To calculate travel times and ray paths accurately and rapidly, we employed the 3-D ray-tracing technique of Zhao et al. (1992), with station elevations taken into account. The nonlinear tomographic problem was solved by iteratively conducting linear inversions. In each iteration perturbations to hypocentral parameters and velocities were determined simultaneously. Further details of the method were given by Zhao et al. $(1992,1994)$.

A number of different grid spacings were tested. Through resolution analyses for different grids, we found that a grid with a horizontal spacing of about $30 \mathrm{~km}$ and a vertical spacing of 12-19 km was adequate for the given distributions of seismic stations and earthquakes. Five horizontal nodal sheets as shown in Fig. 2 were set up at depths of 3, 15, 29, 46, $65 \mathrm{~km}$, respectively, resulting in a total number of 1200 grid nodes. Because 2666 earthquakes were used, the total number of parameters for the velocity structure and hypocentral parameters is $1200+4 \times 2666=11864$. However, velocity solution for a grid node is sought only when there is a 


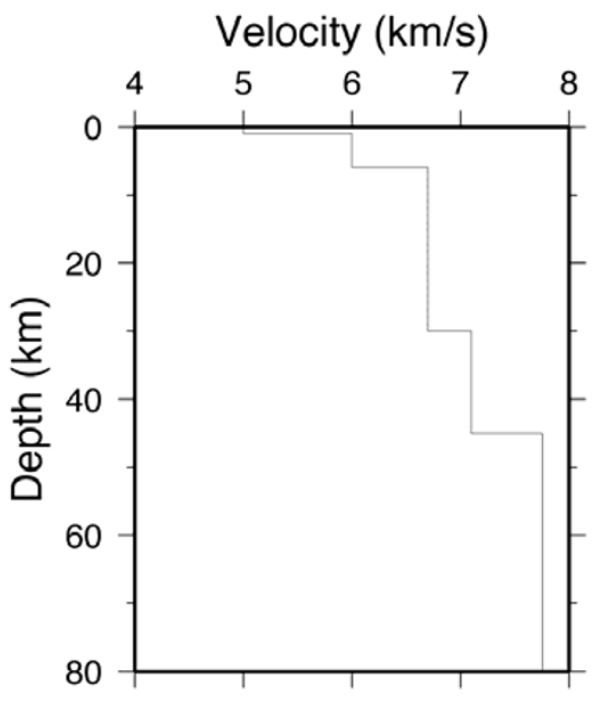

Fig. 4. 1-D $P$-wave velocity model used for routine hypocenter determination in the Vancouver Island area by the Geological Survey of Canada (Rogers, 1983). This model is used as the starting velocity model for the tomographic inversions in this study.
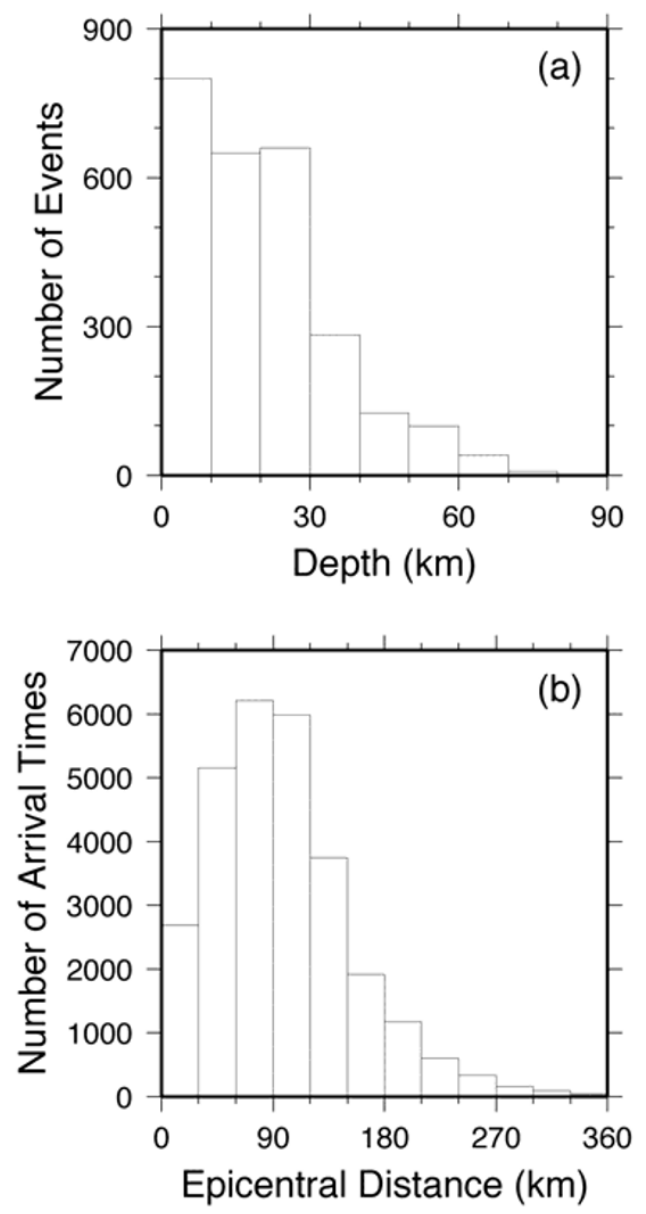

Fig. 5. Statistics of earthquakes used in this study. (a) Number of earthquakes versus focal depth. (b) Number of $P$-wave arrival times versus epicentral distance. sufficient number of ray paths, called hit counts, through its immediate neighborhood. The immediate neighborhood is defined as the space bounded by the 26 surrounding nodes (or 17 for a node on grid boundary). We determined $V_{p}$ for 852 nodes that had at least 10 hit counts. More than $95 \%$ of these nodes had hit counts higher than 50 .

The standard 1-D velocity structure used by the GSC for routine earthquake location in this region (Fig. 4) was used as the starting velocity model. This model is based mainly on seismic refraction studies and represents the average velocity structure of the crust and upper mantle beneath Georgia Strait and Puget Sound in the central part of this area (Rogers, 1983). The velocities at depths greater than $80 \mathrm{~km}$ are fixed at the value of the 1-D model. This may slightly affect the results between 65 and $80 \mathrm{~km}$ depths, where the resolution is poor because of the small number of rays paths.

The simplest means to evaluate the resolution of tomography is to invert a synthetic set of travel times and compare the results with the known velocity structure. In this study, we have used the checkerboard resolution test following the procedure of Zhao et al. (1992). The known velocity structure is of the checkerboard type, that is, all nodes are assigned velocity values that deviate from a given model by the same magnitude, but all neighboring nodes have opposite signs of deviation. We first generated synthetic arrival times for this checkerboard structure, using the real earthquake and station locations that yielded the real data. These synthetic arrivals, perturbed by Gaussian noise (standard deviation $0.1 \mathrm{~s}$ ) were then inverted. Where the checkerboard structure is recovered, the resolution is considered to be good. Figure 6 shows the result of the resolution test. The resolution is better near the surface and in the depth range of $25-50 \mathrm{~km}$. In the southern Vancouver Island area, where earthquakes and stations have relatively uniform distributions, the resolution is good. Offshore, where the raypaths all tend to be one-sided (from hypocenters beneath the ocean to stations on land), the resolution is poor.

\section{Results and Discussion}

Using the grid shown in Fig. 2, we simultaneously determined hypocentral parameters and nodal $V_{p}$ perturbations. The inversion reduced the travel time variance (sum of squared travel time residuals) by $47 \%$ of its initial value. Figure 7 shows fractional velocity perturbations $\left(\triangle V / V_{p}\right)$ from the initial 1-D model (Fig. 6) for all the five grid layers. A cross section across southern Vancouver Island (Fig. 2) is shown in Fig. 8, together with the surface heat flow observations along the same profile. The tomography results are generally consistent with the known large-scale structure. For example, the slab first appears on the $29 \mathrm{~km}$ horizontal slice as a high velocity anomaly band running northwest to southeast offshore Vancouver Island and underneath the Olympic Peninsula and extends progressively further inland at 46 and $65 \mathrm{~km}$ depths (Fig. 7). At $46 \mathrm{~km}$ depth, the high velocity anomaly is wider under the Olympic Peninsula than under Vancouver Island, consistent with the shallow slab dip beneath the Olympic Peninsula (Fig. 1). The slab image is not clear and coherent everywhere, probably because the subducted oceanic plate is young (about $8 \mathrm{Ma}$ ) and hence too thin to be well resolved for the whole region with this 

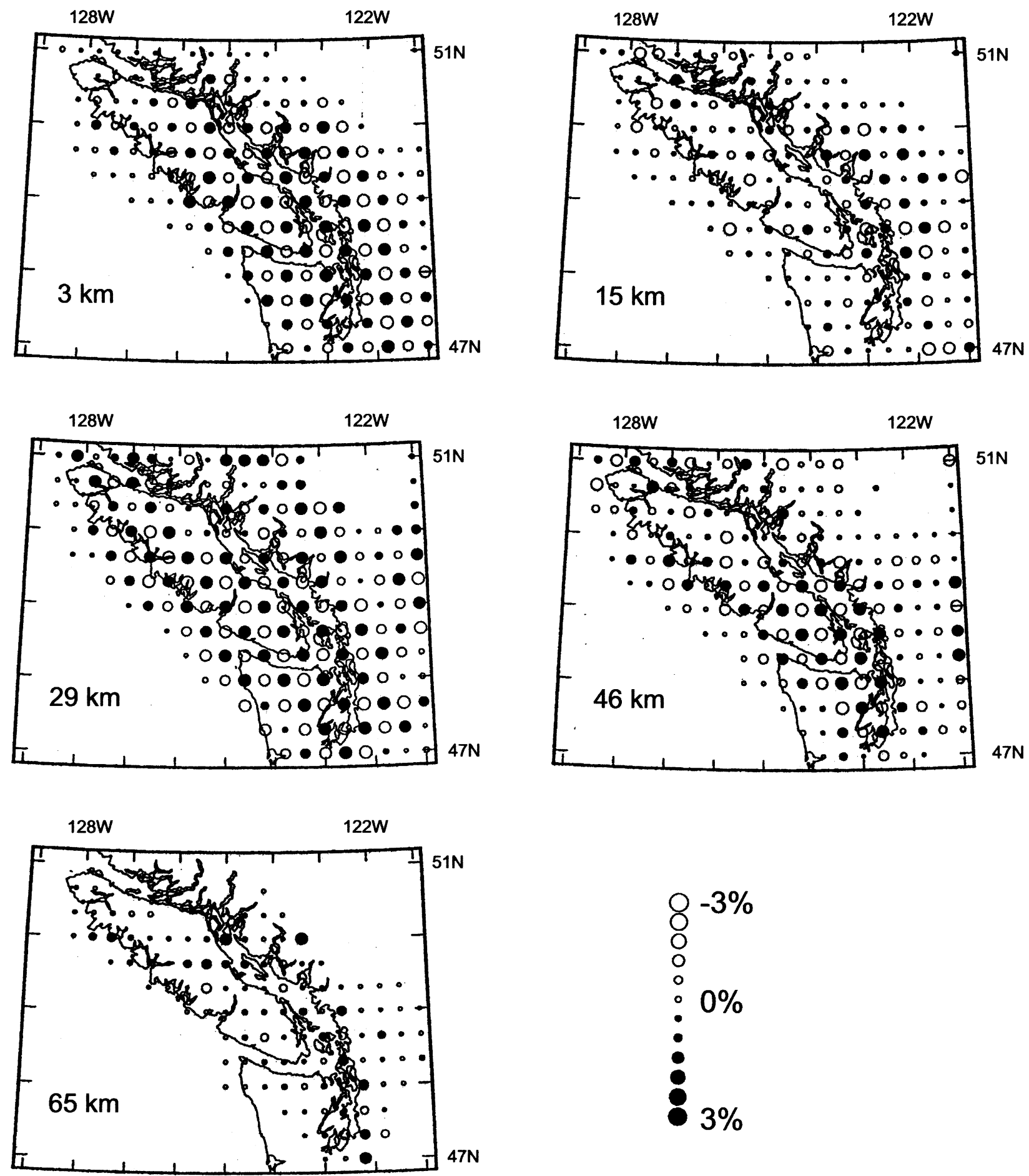

Fig. 6. Result of a checkerboard resolution test (see text) for $P$-wave velocity structure at the five grid depths. Solid and open circles denote high and low velocities, respectively.

density of ray paths. On cross section (Fig. 8), the top of the slab appears as a band of relatively low velocity, probably the combined effect of the oceanic crust and the $E$ layer that both have relatively low velocities. A few of the low velocity patches in the top horizontal slice correlate well with sedimentary basins. The Core rocks of the Olympic Peninsula, the elevated portion of the Tertiary to modern accretionary prism, shows up in the $15 \mathrm{~km}$ slice as a low velocity zone.

The most significant new feature in these tomographic im- ages are the regions of low velocity above the subducted slab. At $46 \mathrm{~km}$ depth a pronounced low velocity anomaly is observed in the region just above the subducting slab and is fairly continuous along strike. This anomaly occurs in the forearc mantle where calculated temperatures are about $500^{\circ} \mathrm{C}$ based on low surface heat flow values $\left(\sim 40 \mathrm{~mW} \mathrm{~m}^{-2}\right)$ and 2-D thermal modelling (Wang et al., 1995). A less continuous, shallower anomaly occurs just west of the volcanic front where surface heat flow values of as least 80 

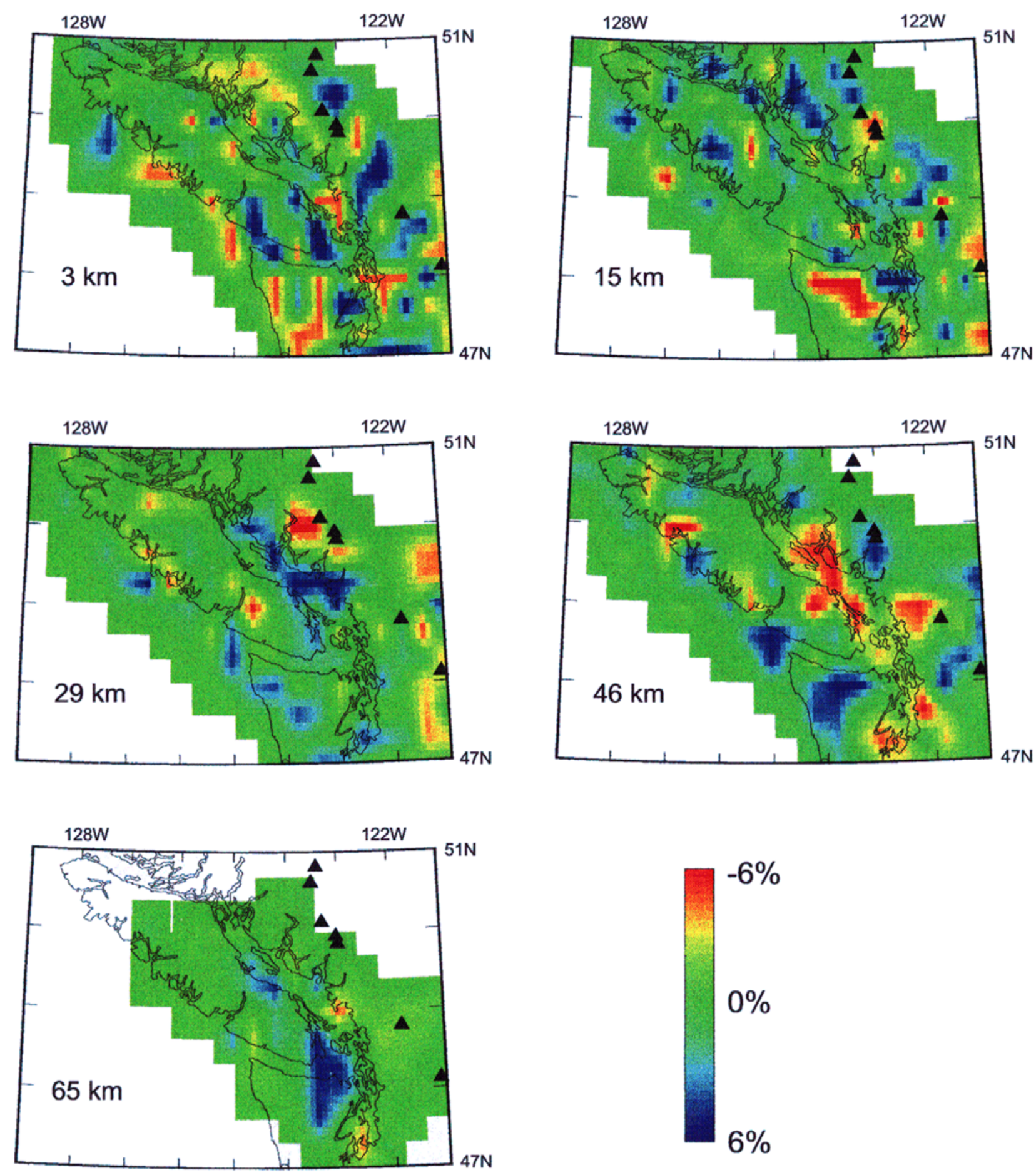

Fig. 7. Fractional $P$-wave velocity perturbations (in \%) from the starting model. Note that the perturbation varies continuously between grid nodes in this tomography method, and hence no smoothing needs to be applied to the results.

$\mathrm{mW} \mathrm{m} \mathrm{m}^{-2}$ indicate a much higher geothermal gradient in the crust (Fig. 8).

The deeper low velocity anomaly is best explained by the presence of partially hydrated mantle, most likely serpentinite. Large volumes of water-rich fluids are liberated from the subducting oceanic crust by metamorphic dehydration reactions associated with transformation of metabasalt to eclogite (e.g., Peacock, 1996). Integrated over millions of years, water released from the subducting slab can potentially hydrate large regions of the overlying mantle. The Cascadia subduction zone is unusually warm owing to the young age of the oceanic plate and the thick insulating sediment cover on the incoming plate. In such a warm subduction zone, eclogite is predicted to form at 40-50 km depth, and large amounts of water-rich fluids will be liberated at this depth range (Peacock and Wang, 1999). At $1 \mathrm{GPa}$, mantle peridotite has a $V_{p}$ of $\sim 8 \mathrm{~km} / \mathrm{s}$ (Christensen, 1966), but pure serpentinite has a $V_{p}$ less than $5 \mathrm{~km} / \mathrm{s}$. The mantle $V_{p}$ decreases dramatically with 

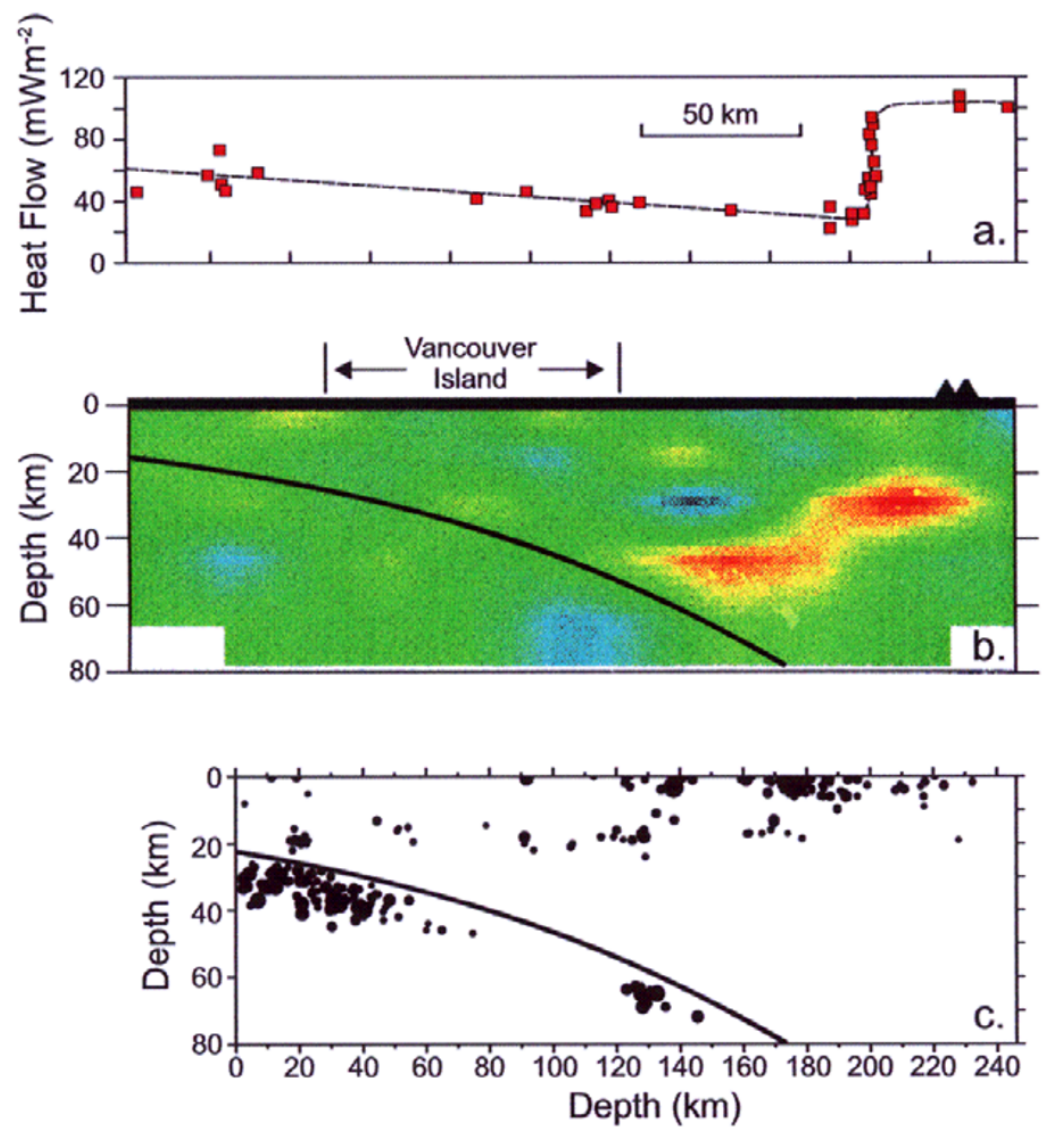

Fig. 8. Surface heat flow along the corridor indicated in Fig. 2 as reported by Hyndman and Lewis (1995) and cross-section view of tomographic results along the same corridor (no vertical exaggeration). The same color scale as in Fig. 7 is used to show the fractional $P$-wave velocity perturbations (in \%) from the starting model. The top surface of the slab, represented by a thick line, was not part of the input or results of the inversion. The top surface was derived from the narrow cross section $(30 \mathrm{~km})$ of earthquake hypocenters shown here. See Fig. 2 for location.

increasing serpentinization, and a 5\% low velocity anomaly can be explained by $15-20 \%$ serpentinization. Slab dehydration may begin at shallower depths, and the previously reported $E$ layer may indicate the resultant hydration of the overlying mantle and crustal material. Unusually low seismic velocities have been observed in the forearc mantle of a number of subduction zones, including Mariana (Hussong and Uyeda, 1982), Alaska (Kisslinger and Lahr, 1991; Zhao et al., 1995), Izu-Bonin (Suyehiro et al., 1996), and Northeast Japan (Zhao et al., 1992), suggesting that serpentinization of forearc mantle may be a common feature of subduction zones.

The shallow low $V_{p}$ region just west of the volcanic front correlates well with the region of high surface heat flow (Fig. 8). In this area, heat flow increases by a factor of two over a distance of $20 \mathrm{~km}$. Such a rapid heat flow transition requires heat sources within the upper crust (Lewis et al., 1988). In addition to the large reflective bands beneath Vancouver Island, smaller but very "bright" reflectors have been observed at shallower depths beneath the mainland (Cook et al., 1988). Lewis et al. (1992) tried to correlate these bright spots with fluids in the crust. The shallow low $V_{p}$ region in the tomographic image may indicate the presence of hot fluids such as melts or water in the crust, perhaps driven by a lower crustal magma intrusion. In cross section (Fig. 8) the two low $V_{p}$ anomalies appear to merge, which might suggest a generic link between the two. For example, water released from the subducting slab migrates upward hydrating parts of the cool overlying mantle, and water that reaches shallower, hotter parts of the mantle to the east might trigger partial melting. The less continuous pattern of the shallow low velocity zones may reflect the fact that magma or water migrates upwards along irregular paths. We note, however, that areas where the shallow low velocity anomalies are observed may simply reflect areas of recent magmatic intrusions into the crust and there may not be a generic link with the deeper low $V_{p}$ region. The answer requires a future refined tomographic model with a higher grid resolution, the addition of $S$-wave velocity structure, and a larger arrival time data base.

Another velocity anomaly that merits some comment is the concentrated low, most obvious on the $15 \mathrm{~km}$ depth slice, near the centre of Vancouver island $\left(49.5^{\circ} \mathrm{N}, 125.5^{\circ} \mathrm{W}\right)$. This is of interest because it is the location of a large $(\mathrm{M}=7.3)$ earthquake in 1946 (Rogers and Hasegawa, 1978) and a region where a significant conductivity anomaly has been detected at mid-crustal depths (Auld et al., 1992). It has been noted that many of the larger crustal earthquakes in Japan correlate with low velocity regions (Hasegawa et al., 1991). A significant velocity low was observed in the epicentral region of the 1995 Kobe earthquake in Japan (Zhao et al., 1996) and has been attributed to the presence of fluids. The Kobe earthquake occurred in a very similar setting to the 
1946 Vancouver Island earthquake, in the potentially fluid rich forearc of a warm subduction zone.

\section{Conclusions}

We have determined the long-wavelength 3-D velocity structure of the Vancouver Island area to a depth of $65 \mathrm{~km}$ by inverting $28,230 \mathrm{P}$-wave arrival times in the Geological Survey of Canada data base. The most significant feature of the tomographic image is an extensive low velocity zone above the subducted plate at about $45 \mathrm{~km}$ depth. We interpret this low velocity zone as being caused by the presence of hydrated (serpentinized) mantle, with a supply of water from the metamorphic dehydration of the subducted plate. The previously observed electrically conductive band of seismic reflectors beneath Vancouver Island (the $E$ layer) may be the result of slab dehydration at shallower depths. The dehydration reaction peaks at temperatures around $500^{\circ} \mathrm{C}$ and $40-50$ $\mathrm{km}$ depth, resulting in the extensive low velocity anomalies. The tomography results also show smaller and less continuous low velocity patches at shallower depths just west of the volcanic front, coincident with an abrupt eastward increase in surface heat flow. These shallow anomalies may indicate the presence of newly intruded magma and/or free water.

Acknowledgments. Part of the data used are arrival times recorded by the seismic network of the University of Washington provided on a routine exchange with the Geological Survey of Canada for earthquakes near the Canada-USA border. Assistance by C. Spindler in preparing the data used in this study is greatly appreciated. Geological Survey of Canada contribution 2000152.

\section{References}

Auld, D. R., S. E. Dosso, D. W. Oldenburg, and L. K. Law, Monitoring temporal change in conductivity in the central Vancouver Island region, an area with past large earthquakes, Can. J. Earth Sci., 29, 601-608, 1992.

Benz, H. M., G. Zandt, and D. H. Oppenheimer, Lithospheric structure of northern California from teleseismic images of the upper mantle, $J$. Geophys. Res., 97, 4791-4807, 1992.

Bostock, M. G. and J. C. VanDecar, Upper mantle structure of the northern Cascadia subduction zone, Can. J. Earth Sci., 32, 1-12, 1995.

Cassidy, J. F. and R. M. Ellis, Shear wave constraints on a deep crustal reflective zone beneath Vancouver Island, J. Geophys. Res., 96, 19,84319,851, 1991.

Cassidy, J. F. and R. M. Ellis, S-wave velocity structure of the northern Cascadia subduction zone, J. Geophys. Res., 98, 4407-4421, 1993.

Christensen, N., Elasticity of ultrabasic rocks, J. Geophys. Res., 71, 5921$5931,1966$.

Clowes, R. M., C. A. Zelt, J. R. Amor, and R. M. Ellis, Lithospheric structure in the souther Canadian Cordillera from a network of seismic refraction lines, Can. J. Earth Sci., 32, 1485-1513, 1996.

Clowes, R. M., D. J. Baird, and S. A. Dehler, Crustal structure of the Cascadia subduction zone, southwestern British Columbia from potential field and seismic studies, Can. J. Earth Sci., 34, 317-335, 1997.

Cook, F. A., A. G. Green, P. S. Simony, R. A. Price, R. Parrish, B. Milkereit, P. L. Gordy, R. L. Brown, K. C. Coflin, and C. Patenaude, Lithoprobe seismic reflection structure of the southern Canadian Cordillera: Initial results, Tectonics, 7, 157-180, 1988.

Crosson, R. S. and T. J. Owens, Slab geometry of the Cascadia subduction zone beneath Washington from earthquake hypocenters and teleseismic converted waves, Geophys. Res. Lett., 14, 824-827, 1987.

Davis, E. E. and R. D. Hyndman, Accretion and recent deformation of sediments along the northern Cascadia subduction zone, Geol. Soc. Am. Bull., 101, 1465-1480, 1989.

Flück, P., R. D. Hyndman, and K. Wang, Three-dimensional dislocation model for great earthquakes of the Cascadia subduction zone, J. Geophys. Res., 102, 20,539-20,550, 1997.

Harris, R. A., H. M. Iyer, and P. B. Dawson, Imaging the Juan de Fuca plate beneath southern Oregon using teleseismic P wave residuals, J. Geophys.
Res., 96, 19,879-19,889, 1991.

Hasegawa, A., D. Zhao, S. Hori, A. Yamamoto, and S. Horiuchi, Deep structure of the northeastern Japan arc and its relationship to seismic and volcanic activity, Nature, 352, 683-689, 1991.

Hussong, D. M. and S. Uyeda, Tectonic processes and the history of the Mariana arc: A synthesis from results of DSDP Leg 60, Init. Rep. Deep Sea Drilling Proj., 60, 909-929, 1982.

Hyndman, R. D., Dipping seismic reflectors, electrically conductive zones, and trapped water in the crust over a subduction plate, J. Geophys. Res., 93, 13,391-13,405, 1988.

Hyndman, R. D., The Lithoprobe corridor across the Vancouver Island continental margin: The structural and tectonic consequences of subduction, Can. J. Earth Sci., 32, 1777-1802, 1995.

Hyndman, R. D. and T. J. Lewis, Review: The thermal regime along the southern Canadian Cordillera Lithoprobe corridor, Can. J. Earth Sci., 32, 1611-1617, 1995.

Hyndman, R. D., C. J. Yorath, R. M. Clowes, and E. E. Davis, The northern Cascadia subduction zone at Vancouver Island: Seismic structure and tectonic history, Can. J. Earth Sci., 27, 313-329, 1990.

Kisslinger, E. and J. C. Lahr, Tomographic image of the Pacific slab under southern Alaska, Eclogae Geol. Helv. 84, 297-315, 1991.

Kurtz, R. D., J. M. Delaurier, and J. C. Gupta, A magnetotelluric sounding across Vancouver Island detects the subducting Juan de Fuca plate, Nature, 321, 596-599, 1986.

Kurtz, R. D., J. M. Delaurier, and J. C. Gupta, The electrical conductivity distribution beneath Vancouver Island: A region of active plate subduction, J. Geophys. Res., 95, 10,929-10,946, 1990.

Lees, J. M. and R. S. Crosson, Tomographic inversion for three-dimensional velocity structure at Mount St. Helens using earthquake data, J. Geophys. Res., 94, 5716-5728, 1989.

Lees, J. M. and R. S. Crosson, Tomographic imaging of local earthquake delay times for three-dimensional velocity variation in western Washington, J. Geophys. Res., 95, 4763-4776, 1990.

Lewis, T. J., W. H. Bentkowski, E. E. Davis, R. D. Hyndman, J. G. Souther, and J. A. Wright, Subduction of the Juan de Fuca plate: Thermal consequences, J. Geophys. Res., 93, 15,207-15,225, 1988.

Lewis, T. J., W. H. Bentkowski, and R. D. Hyndman, Crustal temperatures near the Lithoprobe Southern Canadian Cordillera Transect, Can. J. Earth Sci., 29, 1197-1214, 1992.

Michaelson, C. A. and C. S. Weaver, Upper mantle structure from teleseismic $\mathrm{P}$ arrivals in Washington and northern Oregon, J. Geophys. Res., 91, 2077-2094, 1986.

Moran, S. C., J. M. Lees, and S. D. Malone, P wave crustal velocity structure in the greater Mount Rainier area from local earthquake tomography, $J$. Geophys. Res., 104, 10,775-10,786, 1999.

Peacock, S. M., Thermal and petrological structure of subduction zones, in Subduction: Top to Bottom, edited by G. Bebout, D. W. Scholl, S H. Kirby, and J. P. Platt, pp. 119-133, American Geophysical Union, Washington, D.C., 1996.

Peacock, S. M. and K. Wang, Seismic consequences of warm versus cool subduction metamorphism: Examples from Southwest and Northeast Japan, Science, 286, 937-939, 1999.

Rasmussen, J. and E. Humphreys, Tomographic image of the Juan de Fuca plate beneath Washington and western Oregon using teleseismic P-wave travel times, Geophys. Res. Lett., 15, 1417-1420, 1988.

Riddihough, R. P., Gravity and structure of an active margin-British Columbia and Washington, Can. J. Earth Sci., 16, 350-363, 1979.

Rogers, G. C., Seismotectonics of British Columbia, PhD thesis, University of British Columbia, Vancouver, British Columbia, 247 pp., 1983.

Rogers, G. C. and H. S. Hasegawa, a second look at the British Columbia earthquake of 23 June, 1946, Bull. Seism. Soc. Am., 68, 653-676, 1978.

Rogers, G. C., C. Spindler, and R. D. Hyndman, Seismicity along the Vancouver Island Lithoprobe Corridor, in Proceedings of the Project Lithoprobe: Southern Canadian Cordillera Transect Workshop, pp. 166-169, University of Calgary, Calgary, Alberta, 1990.

Spence, G. D. and N. A. Mclean, Seismic structure across the active subduction zone of western Canada, Can. J. Earth Sci., 36, 1999 (in press).

Spence, G. D., R. D. Hyndman, E. E. Davis, and C. J. Yorath, Seismic structure of the northern Cascadia accretionary prism: Evidence from new multichannel seismic reflection data, in Continental Lithosphere. Deep Reflections, Geodynamics 22, pp. 257-263, American Geophysical Union, Washington, D.C., 1991

Stanley, D., A. Villaseñor, and H. Benz, Subduction zone and crustal dynamics of western Washington: A tectonic model for earthquake hazards evaluation, U.S. Geological Survey Open-File Report 99-311, 1999. 
Suyehiro, K., N. Takahashi, Y. Ariie, Y. Yokoi, R. Hino, M. Shinohara, T. Kanazawa, N, Hirata, H. Tokuyama, and A. Taira, Continental crust, crustal underplating, and low-Q upper mantle beneath and oceanic island arc, Science, 272, 390-392, 1996.

Taber, J. J. and S. W. Smith, Seismicity and focal mechanisms associated with the subduction of the Juan de Fuca plate beneath the Olympic Peninsula, Washington, Bull. Seism. Soc. Am., 75, 237-249, 1985.

VanDecar, J. C., Upper mantle structure of the Cascadia subduction zone from non-linear teleseismic travel-time inversion, $\mathrm{Ph}$.D. thesis, University of Washington, Seattle, Washington, 1991.

Verdonck, D. and G. Zandt, Three-dimensional crustal structure of the Mendocino triple junction region from local earthquake travel times, J. Geophys. Res., 99, 23,843-23,858, 1994.

Wahlstrom, R. and G. C. Rogers, Relocation of earthquakes west of Vancouver Island, British Columbia, 1965-1983, Can. J. Earth Sci., 29, 953-961, 1992.

Wang, K., T. Mulder, G. C. Rogers, and R. D. Hyndman, Case for very low coupling stress on the Cascadia subduction fault, J. Geophys. Res., 100 12,907-12,918, 1995.

Zelt, B. C., R. M. Ellis, and R. M. Clowes, Crustal velocity structure in the eastern Insular and southernmost Coast Belts, Can. J. Earth Sci., 30, 1014-1027, 1993.

Zelt, B. C., R. M. Ellis, and R. M. Clowes, Inversion of three-dimensional wide-angle seismic data from the southwestern Canadian Cordillera, $J$ Geophys. Res., 101, 8503-8529, 1996.

Zhao, D., A. Hasegawa, and S. Horiuchi, Tomographic imaging of $\mathrm{P}$ and $\mathrm{S}$ wave velocity structure beneath northeastern Japan, J. Geophys. Res., 97, 19,909-19,928, 1992.

Zhao, D., A. Hasegawa, and H. Kanamori, Deep structure of Japan subduction zone as derived from local, regional, and teleseismic events, $J$. Geophys. Res., 99, 22,313-22,329, 1994.

Zhao, D., D. Christensen, and H. Pulpan, Tomographic imaging of the Alaska subduction zone, J. Geophys. Res., 100, 6487-6504, 1995.

Zhao, D., H. Kanamori, H. Negishi, and D. Wiens, Tomography of the source area of the 1995 Kobe earthquake: evidence for fluids at the Hypocenter?, Science, 274, 1891-1893, 1996.

D. Zhao (e-mail: zhao@sci.ehime-u.ac.jp), K. Wang, G. C. Rogers (e-mail: Rogers@pgc.nrcan.gc.ca), and S. M. Peacock 